Jahrbuch

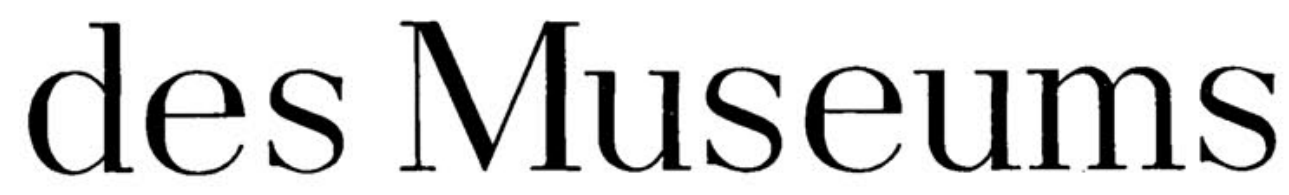

fürVölkerkunde

zu Leipzig

BAND XXX

AKADEMIE-VERLAG - B ERLIN 1975 



\title{
JAHRBUCH \\ DES MUSEUMS FÜR VÖLKERKUNDE ZU LEIPZIG
}

\author{
BAND XXX
}

HERAUSGEGEBEN VOM DIREKTOR

AKADE M IE-VERLAG - BERLIN

1975 


\section{Redaktion: Rolf Krusche}

Die Autoren sind für den Inhalt ihrer Abhandlungen selbst verantwortliche

Redaktionsschluß: 20. Februar 1974

Karten: THомаS

Fotos: Ernst, Himmelheber, Holas, Krusche, Hänse, WieckHorst, MÜller:

Zeichnungen: THOMAS

Alle Rechte vorbehalten, insbesondere das der Ubersetzung in fremde Sprachen

(C) 1975 by Museum für Völkerkunde zu Leipzig

Erschienen im Akademie-Verlag, 108 Berlin, Leipziger Str. 3-4

Lizenznummer . $202 \cdot 100 / 121 / 75$

Gesamtherstellung: IV/2/14 VEB Druckerei "Gottfried Wilhelm Leibniz*, 445 Gräfenhainichen/DDR - 4458

Bestellnummer . $7524274(2085 / \mathrm{II} / 16) \cdot$ LSV 0705

Printed in GDR

EVP 35,- 